\title{
FROM THE SYNTHESIS AND CHARACTERIZATION OF METHACRYLATED FATTY ACIDS BASED PRECURSORS TO SHAPE MEMORY POLYMERS.
}

\author{
Guillermina Capiel, Norma. E. Marcovich, Mirna. A. Mosiewicki* \\ Instituto de Investigaciones en Ciencia y Tecnología de Materiales (INTEMA), Facultad de Ingeniería, \\ Universidad Nacional de Mar del Plata - CONICET, Mar del Plata, Argentina. \\ *Corresponding author: mirna@fi.mdp.edu.ar
}

\begin{abstract}
Fatty acid based monomers have been synthesized by a one step reaction from oleic orlauric acids andglycidyl methacrylateto be later used in polymer formulations. Different times of reaction, amount of catalyst and initial ratio of reactives were evaluated, obtaining conversions higher than 0.9 for the best conditions. The obtained monomers are interesting alternatives to the synthetics ones since they combine low cost with environmental advantages (i.e. higher bio-carbon content). These polymeric precursors were reacted separately in cationic and free radical polymerizations with styrene (50 wt.\%) to evaluate their potential as greener monomers. The lauric acid monomer and the free radical nolymerization were the alternatives that produced the elastomeric materials with higher glass transition temperatures and storage moduli. These facts were related to the less plasticizing effect of the shorter fatty acid chain, in comparison with that of the oleic acid based monomer, and to a lower free volume in the formed structure during curing. Moreover, all the obtained polymers exhibited shape memory properties that can be activated by temperature changes.
\end{abstract}

This article has been accepted for publication and undergone full peer review but has not been through the copyediting, typesetting, pagination and proofreading process which may lead to differences between this version and the Version of Record. Please cite this article as doi: $10.1002 /$ pi.5744 
Keywords: Fatty acids;Methacrylated fatty acid monomers; Renewable resources;Shape memory effect.

\section{Introduction}

Traditional polymeric materials based on petrochemical resources are widely used in many applications ranging from packaging, consumer goods and sport equipments to materials for automotive, marine and aerospace industries. The worldwide increasing concerns regarding sustainability and environmental issues have boosted a growing interest in the development of new bio-based materials for its use in various applications ${ }^{1}$. In this way, vegetable oils and its derived fatty acids are excellent alternatives to petrochemical raw materials due to their high availability, renewable character and chemical versatility ${ }^{2}$.Accordingly, during the last years many efforts have been made in order to obtain novel vegetable oil and fatty acid based polymer precursors and materials ${ }^{3-5}$.

Triglycerides are the main constituents of vegetable oils; they are triesters formed from glycerol and three fatty acids ${ }^{6}$. Since vegetable oils are natural products they show some iation depending on the plant, the season and the growing conditions ${ }^{6,7}$. Most common oils contain fatty acids with chain lengths of $14-22 \mathrm{C}$ atoms, which can be saturated or can present one or more than one unsaturation conjugated or not. Due to their structure (presence of ester groups and double bonds) they can be chemically modified in order to introduce new functional groups and then, the obtained monomers can be polymerized in order to prepare materials exhibiting a broad range of properties ${ }^{6}$. A wide chemistry such as epoxidation, acrylation, methacrylation, transesterification, etc. can be implemented to 
triglycerides and fatty acids to obtain precursors of thermoset resins ${ }^{8}$. Probably the most frequent modification applied to vegetable oils, as well as to their derived fatty acids, is the epoxidation (including the cases where the oxirane ring is opened to synthesize biopolyols). These modified products can be further reacted with anhydrides, isocyanates, can be cationically polymerized, or modified using olefin metathesis, thiol-ene addition, etc. ${ }^{9-}$ ${ }^{13}$ Moreover, the epoxidation of the double bonds followed by the addition of acrylic acid has been reported as an interesting synthesis pathway for obtaining acrylated fatty acids ${ }^{10,14,15}$. The resulting functionalized monomers were reactive enough to produce high molecular weight polymers by free radical polymerization ${ }^{14,15}$.Considering specifically fatty acids, the chemical functionalization through the carboxylic group could be performed. In this line, the use of glycidyl methacrylate, an ethylenic group monomer with an oxirane group, to modify the fatty acids was proved to be an efficient method ${ }^{15-17}$. The resulted adducts of the reaction of GMA and fatty acids would be mostly monomers which would have a vinyl group, a hydroxyl group, and an alkenyl double bond if the starting fatty acid is unsaturated ${ }^{16}$. This type of reaction-addition synthesis has been used to produce vegetable oil-based polyols with high hydroxyl equivalent weight ${ }^{18}$, methacrylated fatty acid monomers to be used as diluent in vinyl ester based polymers ${ }^{17,19,20}$, in triglyceride-based thermosetting resins ${ }^{21}$ and as one of the components for emulsion paints to improve the emulsion film property ${ }^{16}$. Moreover, this synthesis route could also be applied to modify saturated fatty acids like lauricone, with the additional advantage of adding to itterminal unsaturations that could be further polymerized by free radical polymerization, for example. 
Shape memory polymers are materials that can be mechanically deformed and retain a temporary shape, until an appropriate external stimulus (usually heat) is applied so that the original (permanent) shape is recovered ${ }^{22,23}$. They can be thermoplastics orthermosetsand their transformation temperature (switch temperature) can be the melting or the glass transition temperature $(\mathrm{Tg})$ of a 'soft' phase. For a thermoset polymer, the cross-links are net points where the memory of the permanent shape is stored, while the free polymer chains between the cross-links are switching segments that obtain increased mobility above $\mathrm{Tg}^{22,24}$. Although many works related to synthesis and characterization of oleochemical based monomers and polymers have been reported, the simplicity in the synthesis of the precursors (low amount of steps of chemical modification in raw materials) in conjunction with high biomass content and functional properties (shape memory) in the final polymer are characteristics rarely found in the same material. As few examples, it can be mentioned the works of Meiorin et. al. ${ }^{24,25}$ that report the shape memory study of thermoset materials obtained from cationic copolymerization of raw tung oil and styrene. The focus of this work is thus, to synthesize monomers with high bio-based content by means of a simple one-step reaction-addition procedure between glycidyl methacrylate and fatty acids to be used as precursors of shape memory polymers. Two different fatty acids, oleicand lauric acid,are used as starting raw materials. The synthesis parameters (reaction time, catalyst concentration) were optimized for the obtaining of methacrylated oleic acid and then used in the synthesis of the methacrylatedlauric acid based monomers. The obtained products were carefully characterized and the suitability of obtaining polymeric materials with shape 
memory behavior via radical and cationic polymerization of these methacrylated monomers with styrene was also tested.

\section{Materials}

Oleic acid (OA), lauric acid (LA) and glycidyl methacrylate (GMA) used in the synthesis of themethacrylatedfatty acidmonomerswere supplied by Sigma Aldrich;thecatalyst, 2Methylimidazole, was supplied by Fluka. Materials were used as received.

The polymeric materials were obtained using the synthesized monomers and styrene supplied by Kubo.Boron trifluoride diethyl etherate $\left(\mathrm{BF}_{3} . \mathrm{OEt}_{2}\right)$ was obtained from SigmaAldrichand used as the initiator of the cationic reaction. Benzoyl peroxide (BPO)was obtained from Akzo Nobel Chemicals and used as the initiator of the free-radical reaction.

\section{Methods and techniques}

\subsection{Synthesis of fatty acid monomers}

e addition of the fatty acid (OA or LA) to the GMA was performed by mixing it with the catalyst (2-methylimidazole) in a stirred glass vessel at $70{ }^{\circ} \mathrm{C}$. A thermostatic water bath was used to control the temperature. Different reaction times, weight percentages of catalyst and reactants molar ratio were tested in order to optimize the synthesis of the OAbased monomers. The optimized conditions were used for the LA-based one. The nomenclature used in each synthesis is summarized in Table 1. 
Table 1. Nomenclature and conditions used in each monomer synthesis.

\begin{tabular}{|c|c|c|c|c|}
\hline Synthesis & $\begin{array}{c}\text { Fatty } \\
\text { acid }\end{array}$ & $\begin{array}{c}\text { Fatty acid:GMA } \\
\text { molar ratio }\end{array}$ & $\begin{array}{c}\text { Catalyst } \\
\text { (wt. \%) }\end{array}$ & $\begin{array}{c}\text { Reaction } \\
\text { time } \\
\text { (hours) }\end{array}$ \\
\hline S1 & OA & $1: 1$ & 1 & 2.5 \\
\hline S2 & OA & $1: 1$ & 2 & 2.5 \\
\hline S3 & OA & $1: 1$ & 1 & 5.0 \\
\hline S4 & OA & $1: 1$ & 2 & 5.0 \\
\hline S5 & OA & $1: 1.1$ & 2 & 5.5 \\
\hline S6 & LA & $1: 1.1$ & 2 & 5.5 \\
\hline
\end{tabular}

\subsection{Acid number, hydroxyl number and epoxy value}

Acid number, epoxy value and hydroxyl number techniques described elsewhere ${ }^{26,27}$ were used to characterize fatty acids and fatty acid based monomers.

\subsection{Size exclusion chromatography (GPC)}

GPC analyses were performed by a Shimadzu Prominence GPC system equipped with Shim-pack GPC-803 and Shim-pack GPC-804 columns. The columns were equilibrated and run at $25^{\circ} \mathrm{C}$ using tetrahydrofuran (THF) as the elution solvent at a flow rate of $1 \mathrm{~mL}$ $\min ^{-1}$. The column effluent was monitored by a RID-20A Prominence Shimadzu refractive index detector. Samples were prepared by dissolving $5 \mathrm{mg}$ sample in $1 \mathrm{~mL}$ THF.

\subsection{Fourier transform infrared spectroscopy (FTIR)}

FT-IR spectra of the raw materials and synthesized monomers were recorded using the attenuated totalreflection method (ATR) by means of a Thermo Scientific Nicolet6700 FT-IR 
spectrometer. The spectra were obtained overthe range of $500-4000 \mathrm{~cm}^{-1}$ with a resolution of $4 \mathrm{~cm}^{-1}$ and the reported results are the average of 32 scans.

\subsection{Nuclear magnetic resonance spectroscopy ('HNMR)}

${ }^{1} \mathrm{H}$ NMR spectra of the reactants and the synthesized monomers were recorded on a Bruker AM500 spectrometer $(500 \mathrm{MHz})$ using $\mathrm{CDCl}_{3}$ assolvent at $25^{\circ} \mathrm{C}$.

\subsection{Preparation of polymeric materials}

The monomers obtained from syntheses S5 and S6 were selected to be used in the preparation of polymeric materials. Mixtures of 50 wt. \% of styrene and the corresponding fatty acid monomer were used to prepare materials by means of cationic polymerization (using 1 wt. \% $\mathrm{BF}_{3} . \mathrm{OEt}_{2}$ as initiator) and by means of radical polymerization (using $1 \mathrm{wt} . \%$ $\mathrm{BPO}$ as the initiator). The reactive mixtures were manually homogenized and then poured into a glass mold. The curing cycle included two hours at $80{ }^{\circ} \mathrm{C}$ and two hours at $150{ }^{\circ} \mathrm{C}$. The prepared materials are summarized in Table 2.

Table 2.Polymeric materials prepared from the fatty acid monomers.

\begin{tabular}{|c|c|c|}
\hline Material & Composition & $\begin{array}{c}\text { Polymerization } \\
\text { type }\end{array}$ \\
\hline MOA-ST-cationic & S5-styrene $50-50$ wt. \% & cationic \\
\hline MOA-ST-radical & S5-styrene $50-50$ wt. \% & radical \\
\hline MLA-ST-cationic & S6-styrene 50-50 wt. \% & cationic \\
\hline MLA-ST-radical & S6-styrene 50-50 wt. \% & radical \\
\hline
\end{tabular}




\subsection{Dynamic mechanical analysis (DMA)}

The dynamic mechanical properties of the materials were determined with an Anton Paar Physica MCR rheometer. Torsion geometry was used with rectangular specimens of $10 \mathrm{~mm}$ $\mathrm{x} 40 \mathrm{~mm}$ and $2 \mathrm{~mm}$ in thickness. Measurements were performed as temperature sweeps in the range-20 to $150{ }^{\circ} \mathrm{C}$, at a heating rate of $5^{\circ} \mathrm{C} / \mathrm{min}$.

The frequency and the applied deformation were kept at $1 \mathrm{~Hz}$ and $0.05 \%$, respectively, to ensure working in the linear viscoelastic range. The glass transition temperatures $(\mathrm{Tg})$ were arbitrarily taken as the temperatures at which a maximum in the $\tan \delta$ curve was observed.

\section{8 Shape memory tests}

Rectangular bar specimens of $10 \mathrm{~mm} \times 40 \mathrm{~mm} \times 2 \mathrm{~mm}$ (thickness) were used to investigate the shape memory behavior. The test specimens were immersed in a hot water bath maintained at $70{ }^{\circ} \mathrm{C}$ and held for $20 \mathrm{~s}$. Then, they were deformed to ' $\mathrm{U}$ ' shape and cooled down to $15^{\circ} \mathrm{C}$ in order to fix the temporary shape. The maximum bending angle fixed was almost $0^{\circ}$ for all samples. To evaluate the shape recovery behavior, the deformed sample was again immersed in a hot water bath maintained at $60^{\circ} \mathrm{Cor} 70^{\circ} \mathrm{C}$ (both temperatures ng higher than the Tgs of all materials).The time required by the material to recover its original shape was registered and shape recovering angles $(\theta r)$ at different times were measured. The recovery ratio $(\operatorname{Rr})$ was determined as follows ${ }^{28}$ :

$$
\mathrm{Rr}=100 * \frac{\theta \mathrm{r}}{180^{\circ}}
$$

\section{RESULTS AND DISCUSSION}




\subsection{Synthesis and characterization of the fatty acid based monomers}

The methacrylatedfatty acid monomers were obtained by the chemical addition of the oleic or lauric acid and the GMA as shown in Fig. 1for the main products of the reaction. The synthesis of fatty acid monomers based on oleic acid were performed under different reaction times (2.5 and 5 hours), weight percentages of catalyst ( 1 and 2 wt.\%) and initial amount of reactives(1:1 and 1:1.1 molar ratio,fatty acid:GMA) (Table 1). In the syntheses

S1 to S5 oleic acid was used as a reactant, whilelauric acid was used in synthesis S6, using the conditions that gave the higher conversion value for the oleic acid based monomer.

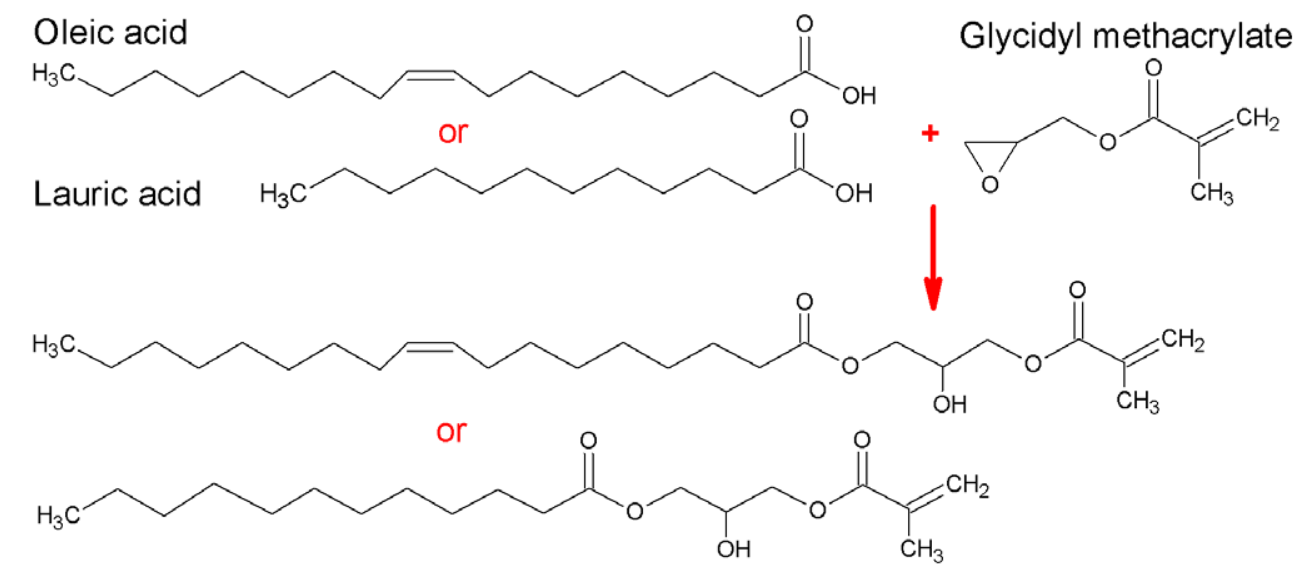

Figure 1. Chemical structure of the reactants (oleic acid, lauric acid and GMA) and the obtained methacrylated fatty acid monomers.

Table 3 shows that all the obtained products present a small amount of free (unreacted) fatty acid, which is denoted in the low acid values. The comparison among different reaction conditions for the synthesis of OA derivatives (S1-S5) shows that the lower acid values, which mean higher conversion, are directed related tolonger reaction times, higher amount of catalyst and the use of a small excess of GMA with respect to the stoichiometry 
relationship between OA and GMA. Regarding synthesis S5 and S6, the agreement of the experimentally obtained $\mathrm{OH}$ numbers with the theoretically expected ones (132 and 165mg $\mathrm{KOH} / \mathrm{g}$ sample, respectively) is noteworthy, but it should be taken into account that there are experimental errors associated to the analytical determination.On the other hand, all synthesized monomers presented null values of epoxy groups, indicating either that the GMA was completely consumed during reaction or that this technique is not sensible enough to detect small amounts of epoxy groups.

Table3.Analytical characterizationof the acrylated fatty acid monomers

\begin{tabular}{|c|c|c|}
\hline Synthesis & $\begin{array}{c}\text { Acid value } \\
\text { (mg KOH/g sample) }\end{array}$ & $\begin{array}{c}\text { Hydroxyl number } \\
\text { (mg KOH/g sample) }\end{array}$ \\
\hline S1 & $48.8 \pm 0.4$ & - \\
\hline S2 & $34.6 \pm 0.3$ & - \\
\hline S3 & $41.0 \pm 0.3$ & - \\
\hline S4 & $29.5 \pm 0.3$ & - \\
\hline S5 & $16.7 \pm 0.1$ & $135.0 \pm 5.0$ \\
\hline S6 & $21.3 \pm 0.1$ & $165.8 \pm 0.3$ \\
\hline
\end{tabular}

The obtained monomers were also analyzed by FTIR; the correspondingspectraforsyntheses $\mathrm{S} 1$ to $\mathrm{S} 6$ are shown in Fig. 2a and 2b.

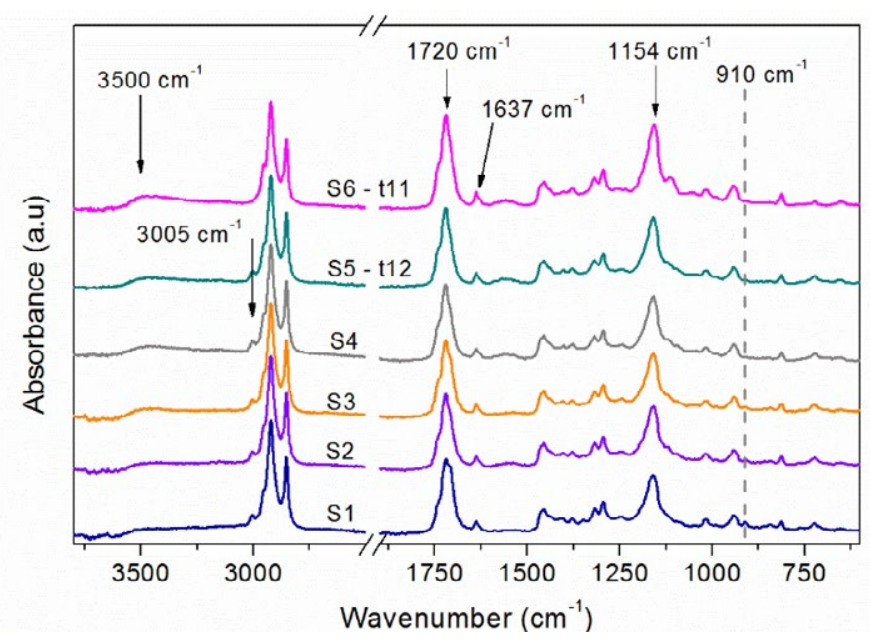

Figure 2a. FTIR spectra of the obtained fatty acid monomers. 


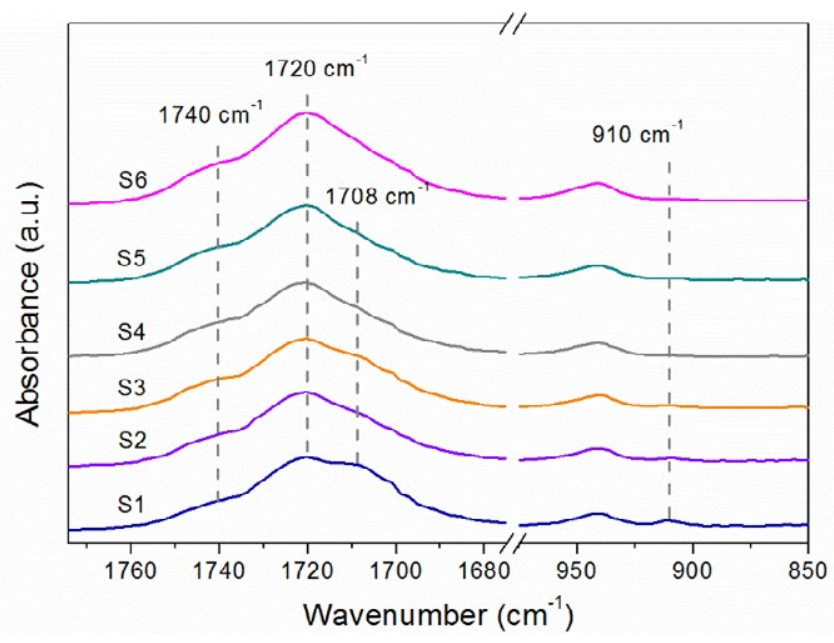

Figure $\mathbf{2 b}$. FTIR spectra of the obtained fatty acid monomers. Insight.

All spectra show three signals at $1720 \mathrm{~cm}^{-1}$ and $1637 \mathrm{~cm}^{-1}$ and $1154 \mathrm{~cm}^{-1}$ corresponding to the stretching of the carbonyl group $\mathrm{C}=\mathrm{O}$, the stretching of the $\mathrm{C}=\mathrm{C}$ bond and the stretching of C-O-C bond, respectively ${ }^{29,30}$. The signal at $3005 \mathrm{~cm}^{-1}$, which is assigned to the absorption of $\mathrm{C}=\mathrm{C}$ bonds in the oleic $\mathrm{acid}^{29}$ is also present in the spectra of synthesis $\mathrm{S} 1$ to $\mathrm{S} 5$, indicating that the unsaturationsin the oleic acid were preserved during the chemical reactions. As expected, this signal is absent in the spectra of the monomer prepared from lauric acid.

The chemical addition involves the disappearance of the epoxy groups from GMA and the acid groups from oleic or lauric acid as well as the appearance of new ester groups. The disappearance of the signal at $910 \mathrm{~cm}^{-1}$ corresponding to the stretching of the $\mathrm{C}-\mathrm{O}$ bond in theepoxy group ${ }^{30}$ can be observed in Fig. 2b. Monomers S1 and S2 present a very small absorption band at this wavenumber,indicating that the chemical reaction did not go to completion. This also confirms that the epoxy value technique was not able to account for these remnant groups. However, this signal is very small in S2 spectra and it is practically 
absent in S3 and S4 spectra. This fact shows that the increase of the catalyst amount (2 wt. $\%$ instead of 1 wt. \%) as well as the increase of the reaction time (5 hours instead of 2.5 hours) had a positive effect on the reaction conversion. In agreement with these results, the disappearance/reduction of the band corresponding to the carbonyl group in the oleic acid, located at $1708 \mathrm{~cm}^{-1}$ is also observed in Fig. 2b. The spectra of S1, S2 and S3 monomers present a small shoulder at that position indicating that not all the oleic acid has been consumed during the reaction, while monomers S4 and S5 do not present appreciably signals associated to the presence of free fatty acids groups, which confirms that longer times and high catalyst concentration lead to purer products (i.e. lower content of unreacted reagents). On the other hand, this technique do not allow us to identify if the small excess of GMA used in obtaining the S5 monomer had also a positive effect on the conversion since not appreciable differences between spectra S4 and S5 are noticed. Moreover, the band at $1695 \mathrm{~cm}^{-1}$ corresponding to the acid group from lauric acid is neither present in the spectra of monomer S6. Furthermore, the appearance of a signal at $1740 \mathrm{~cm}^{-1}$ assigned to the vibration of the ester group ${ }^{30}$ resulting from the chemical addition between the acid and the epoxy groups is observed in all the obtained spectra.

rig. 3 shows the FTIR spectra measured at regular periods of time(30 minutes) during the synthesis S5.In the inset ofFig. 3 (Fig. 3b) the spectra of neat oleic acid is included. It can be clearly seen that the signal corresponding to carbonyl group of free fatty acid at 1708 $\mathrm{cm}^{-1}$ decreases with time while the ester signal at $1740 \mathrm{~cm}^{-1}$ increases, and the carbonyl band from the methacrylate group $\left(1720 \mathrm{~cm}^{-1}\right)$ remains constant. Furthermore, the consumption of the epoxy group is evidenced by the decrease in the intensities of bands 
$910 \mathrm{~cm}^{-1}, 842 \mathrm{~cm}^{-1}$ and $760 \mathrm{~cm}^{-1}$, which are assigned to different vibrations modes of the epoxy group (see Fig. 3c).It is important to remark that the simultaneous decrease of both, carbonyl of free fatty acid and epoxy bands confirms that the reaction occurred in stoichiometric conditions (Fig. 1) and that there were no parallel or side reactions (i.e. epoxy-epoxy reactions).The same procedure was used during the synthesis S6 and the previous observations regarding the simultaneous decrease of the carbonyl and epoxy bands, as well as the increase of the ester peak, apply.

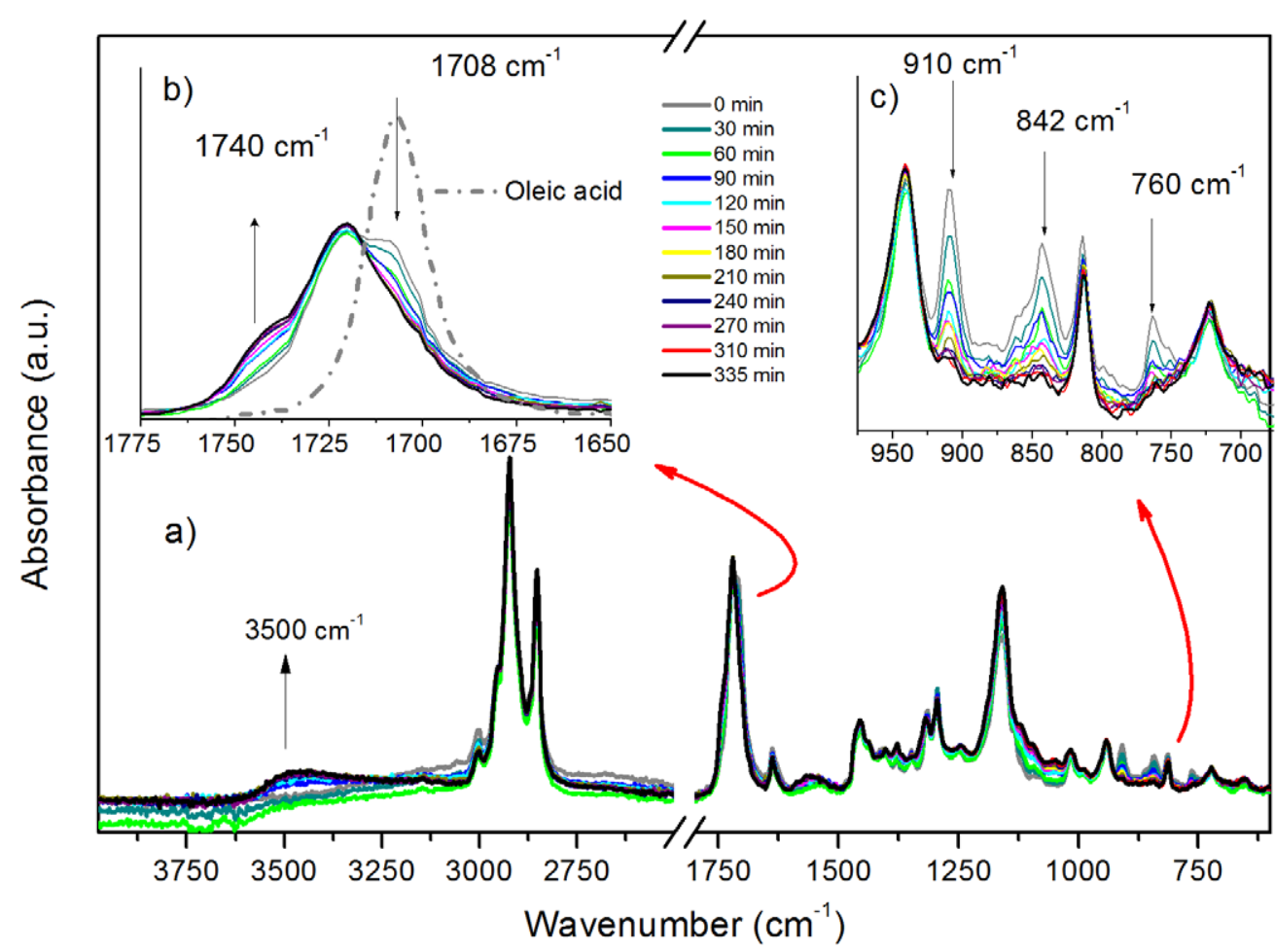

Figure 3. FTIR spectra recorded during the synthesis of the S5 monomers.

Fig. 4 shows the consumption of the epoxy group measured by FTIR as a function of time during the syntheses $\mathrm{S} 5$ and $\mathrm{S} 6$. The calculation was performed by measuring the relative heightof the epoxy peak located at $910 \mathrm{~cm}^{-1}$ (corresponding to the epoxy group) to the heightof the reference peak located at $940 \mathrm{~cm}^{-1}$ (corresponding to the methacrylate group 
from GMA). The epoxy conversion reached in both syntheses is $0.9-0.95$ and they show practically the same kinetic behavior(i.e. reaction rate).Moreover, these conversion values agree pretty well with the low but not null acid values presented in Table 3 for synthesis S5 an S6.Although the disappearance of the acid group $\left(1708 \mathrm{~cm}^{-1}\right)$ and the appearance of the ester group $\left(1740 \mathrm{~cm}^{-1}\right)$ with time are observed in the IR spectra (Fig. 3), both signals are too close to the GMA-carbonyl signal at $1720 \mathrm{~cm}^{-1}$ and, as a consequence, the corroboration of the reaction conversion with time using the acid band would not be accurate. Moreover, the not null acid values reported in Table 3, as well as the GPC chromatograms presented in the next section coincide in indicating that not all the carbonyl groups initially present in the fatty acids reacted with the epoxy groups of the GMA.

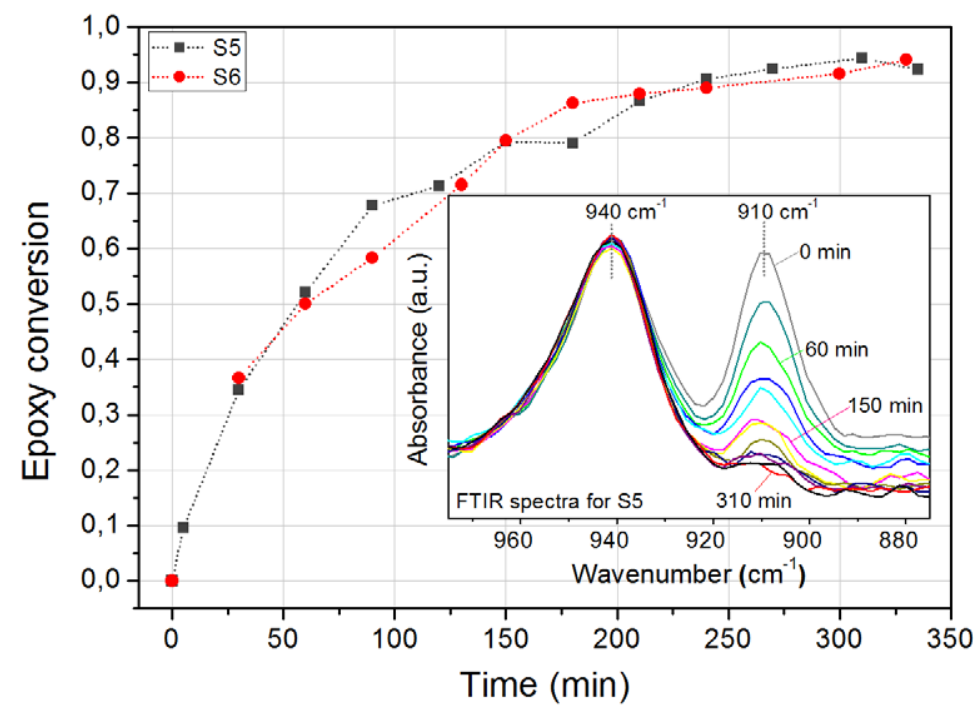

Figure 4.Conversion as a function of time for $\mathrm{S} 5$ and $\mathrm{S} 6$ syntheses. Inset: FTIR spectra showing the peaks used for the kinetic calculation $\left(910\right.$ and $\left.940 \mathrm{~cm}^{-1}\right)$. 
The size exclusion chromatograms of the GMA, oleic and lauric acids, as well as the products obtained from synthesis S5 and S6 are shown in Fig. 5. It is known that highmolecular-weight species cannot diffuse into the small pores of the columns packing and thus they elute first, while lower molecular weight species elute later ${ }^{17,20}$. On the other hand, it is clear that products S5 and S6 have higher molecular weights than oleic and lauric acids, respectively, but also a quite narrow distribution of molecular weights (narrow main peak). It is also clear that the obtained products contain also small amounts of unreacted fatty acids (peaks at 20.8 and 21.5 minutes, respectively) and probably any impurity coming from the GMA (peaks at 21.3-21.5 minutes). These results corroborate the previous ones, that is, that both, oleic and lauric acids reacted with GMA to form higher molecular weight bio-based monomers.

At this point, it is worth to mention that, depending on the synthesis conditions, competitive reactions with the main one (Fig. 1) can take place. Shechter and Wynstrain 1956 studied the competitive reactions between a glycidileter and a carboxylic acid in different reactions conditions $^{31}$. Most of these competitive reactions give species of higher molecular weight than that of the products presented in Figure 1 and some of them can derivate in monomers with functionalities higher than 2. Although the GPC analysis do not show clear signals of species eluded at shorter times than 20.5 and 20.7 minutes corresponding to the times of thedifunctional monomers (MOA and MLA, respectively), very small shoulders can be observed in the spectra at 19.9 min and $20.3 \mathrm{~min}$, for synthesis S5 and S6, respectively. 


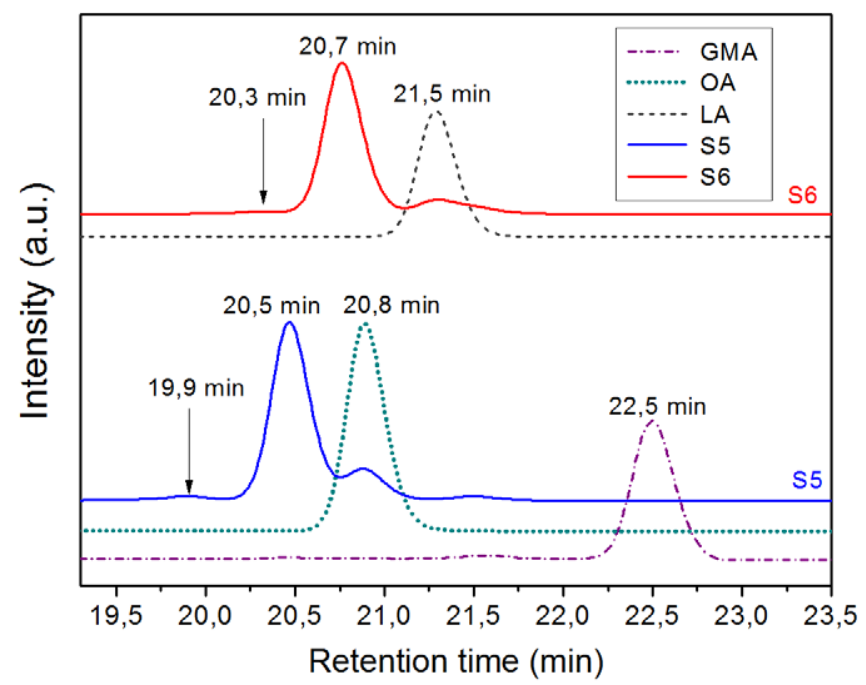

Figure 5.Size exclusion chromatograms of the GMA, oleic acid (OA), lauric acid (LA),S5 (monomer derived from $\mathrm{OA}$ ) and $\mathrm{S} 6$ (monomer derived from $L A$ ).

The reactives and synthesized monomers were analyzed by ${ }^{1} \mathrm{H}$ NMR and the results are shown in Fig.6, 7 and 8. The assignment of the peaks and the areas measured from the spectra are presented in Table 4.For the calculations it was considered that the area of the peaks at0.9 ppm (named with letter "a") corresponds to the $3 \mathrm{H}$ of methyl protons per monomer or per fatty acid. For the analysis of GMA, the signal at 5.61-6.16 ppm was arbitrary associated with 2 protons of the $=\mathrm{CH}_{2}$ group.

The characteristic peaks of lauric acid $\left(-\mathrm{C}_{3}\right.$ at $0.9 \mathrm{ppm}$; backbone $-\mathrm{C}_{2}$ at $1.33 \mathrm{ppm} ; \underline{\mathrm{H}}_{2}-$ $\mathrm{CH}_{2}-\mathrm{COOH}$ at $1.66 \mathrm{ppm}$ and $\mathrm{CH}_{2}-\mathrm{COOH}$ at $2.37 \mathrm{ppm}$ ) are also present in the spectra of the oleic acid, as expected (Fig. 6a and Fig. 6b). Additionally, the latter displays the signals corresponding to the unsaturation of the oleic acid $(-\underline{\mathrm{H}}=$ at $5.37 \mathrm{ppm})$ and to the respective a-methylene group connected with it $\left(\mathrm{C}_{2}-\mathrm{CH}=\mathrm{CH}-\right.$ at 2.04 ppm). GMA spectrum (Fig. 6c) shows a peak at 3.25 ppm and two signals at 2.67 and 2.86 ppm due to the $-\underline{C}_{2}-$ and $-\mathrm{C} \underline{H}-$ protons of the epoxy group respectively. The signals at $4-4.5 \mathrm{ppm}$ are assigned to the 
protons associated with ester groups and the two peaks located at 5.65 and $6.17 \mathrm{ppm}$ correspond to the acrylate group protons. 
Table 4. Chemical shifts, theoretical (theo) and experimental (exp) amounts of protons per molecule obtained from ${ }^{1} \mathrm{H}$ NMR spectra.

\begin{tabular}{|c|c|c|c|c|c|c|c|c|c|c|c|c|c|c|c|}
\hline $\begin{array}{l}\text { Signal } \\
\text { (ppm) }\end{array}$ & Assignment & $\begin{array}{l}\text { GMA } \\
\text { Theo }\end{array}$ & $\begin{array}{l}\text { GMA } \\
\text { Exp }\end{array}$ & $\begin{array}{l}\text { LA } \\
\text { Theo }\end{array}$ & $\begin{array}{l}\text { LA } \\
\text { Exp }\end{array}$ & $\begin{array}{l}\text { OA } \\
\text { Theo }\end{array}$ & $\begin{array}{l}\text { OA } \\
\operatorname{Exp}\end{array}$ & $\begin{array}{l}\text { MOA } \\
\text { Theo }\end{array}$ & $\begin{array}{l}\text { S1 } \\
\text { Exp }\end{array}$ & $\begin{array}{c}\text { S2 } \\
\text { Exp }\end{array}$ & $\begin{array}{c}\text { S3 } \\
\text { Exp }\end{array}$ & $\begin{array}{c}\text { S4 } \\
\text { Exp }\end{array}$ & $\begin{array}{l}\text { S5 } \\
\text { Exp }\end{array}$ & $\begin{array}{l}\text { MLA } \\
\text { Theo }\end{array}$ & $\begin{array}{c}\text { S6 } \\
\text { Exp }\end{array}$ \\
\hline 0.90 & $\mathrm{CH}_{3}-$ & - & - & 3 & 3.00 & 3 & 3.00 & 3 & 2.99 & 3.00 & 3.00 & 3.00 & 3.00 & 3 & 3.00 \\
\hline 1.30 & $-\mathrm{CH}_{2}-$ & - & - & 16 & $\begin{array}{c}16.1 \\
3\end{array}$ & 20 & $\begin{array}{c}20.3 \\
1\end{array}$ & 20 & $\begin{array}{c}20.0 \\
0\end{array}$ & $\begin{array}{c}19.0 \\
8\end{array}$ & $\begin{array}{c}20.0 \\
0\end{array}$ & $\begin{array}{c}20.0 \\
0\end{array}$ & $\begin{array}{c}20.0 \\
0\end{array}$ & 16 & $\begin{array}{c}16.1 \\
9\end{array}$ \\
\hline 1.65 & $\begin{array}{l}-\mathrm{CH}_{2}-\mathrm{CH}_{2}-(\mathrm{C}=\mathrm{O})- \\
\mathrm{O}-\end{array}$ & - & - & 2 & 2.00 & 2 & 1.98 & 2 & 1.99 & 2.02 & 1.98 & 1.94 & 1.94 & 2 & 1.95 \\
\hline 1.98 & $-\mathrm{C}\left(\mathrm{C}_{\mathrm{H}_{3}}\right)=\mathrm{CH}_{2}$ & 3 & 3.01 & - & - & - & - & 3 & \multirow{2}{*}{6.52} & \multirow{2}{*}{5.35} & \multirow{2}{*}{6.58} & \multirow{2}{*}{6.61} & \multirow{2}{*}{6.91} & 3 & 3.39 \\
\hline 2.03 & $-\mathrm{C}_{2}-\mathrm{CH}=\mathrm{CH}-$ & - & - & - & - & 4 & 3.83 & 4 & & & & & & - & - \\
\hline 2.37 & $-\mathrm{CH}_{2}-(\mathrm{C}=\mathrm{O})-\mathrm{O}-$ & - & - & 2 & 1.96 & 2 & 1.98 & 2 & 1.97 & 2.00 & 1.97 & 1.89 & 1.63 & 2 & 1.63 \\
\hline $2.67-2.86$ & $\underline{\mathrm{H}}_{2} \mathrm{C} \stackrel{\stackrel{\mathrm{O}}{\perp} \mathrm{CH}-\mathrm{R}}{-}$ & 2 & 1.97 & - & - & - & - & - & 0.26 & 0.98 & 0.25 & 0.36 & 0.41 & - & 0.23 \\
\hline 3.25 & 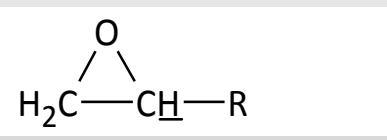 & 1 & 0.94 & - & - & - & - & - & - & 0.31 & - & - & - & - & - \\
\hline 3.80 & $-\mathrm{CH}_{2}-\mathrm{C} \underline{\mathrm{H}}(\mathrm{OH})-\mathrm{CH}_{2}-$ & & & & & & & 1 & * & * & * & * & * & 1 & * \\
\hline $4-4.4$ & $-\mathrm{C}_{2}-\mathrm{O}-(\mathrm{C}=\mathrm{O})-$ & 2 & 1.97 & - & - & - & - & 4 & 4.00 & 2.93 & 4.08 & 5.09 & 4.3 & 4 & 4.36 \\
\hline $3.2-4.6$ & $-\mathrm{CH}_{2}-\mathrm{CH}(\mathrm{O} \underline{\mathrm{H}})-\mathrm{CH}_{2}-$ & - & - & - & - & - & - & 1 & * & * & * & * & * & 1 & * \\
\hline 5.37 & $-\mathrm{CH}=\mathrm{CH}-$ & - & - & - & - & 2 & 1.96 & 2 & 2.03 & 1.92 & 2.02 & 1.96 & 1.96 & - & - \\
\hline $5.61-6.16$ & $-\mathrm{C}\left(\mathrm{CH}_{3}\right)=\mathrm{CH}_{2}$ & 2 & 2.00 & - & - & - & - & 2 & 1.81 & 1.43 & 1.85 & 1.76 & 2.00 & 2 & 2.04 \\
\hline
\end{tabular}


*the overlapping of these signals make difficult to assign a unique and exact experimental value to compare it with the theoretical one. 

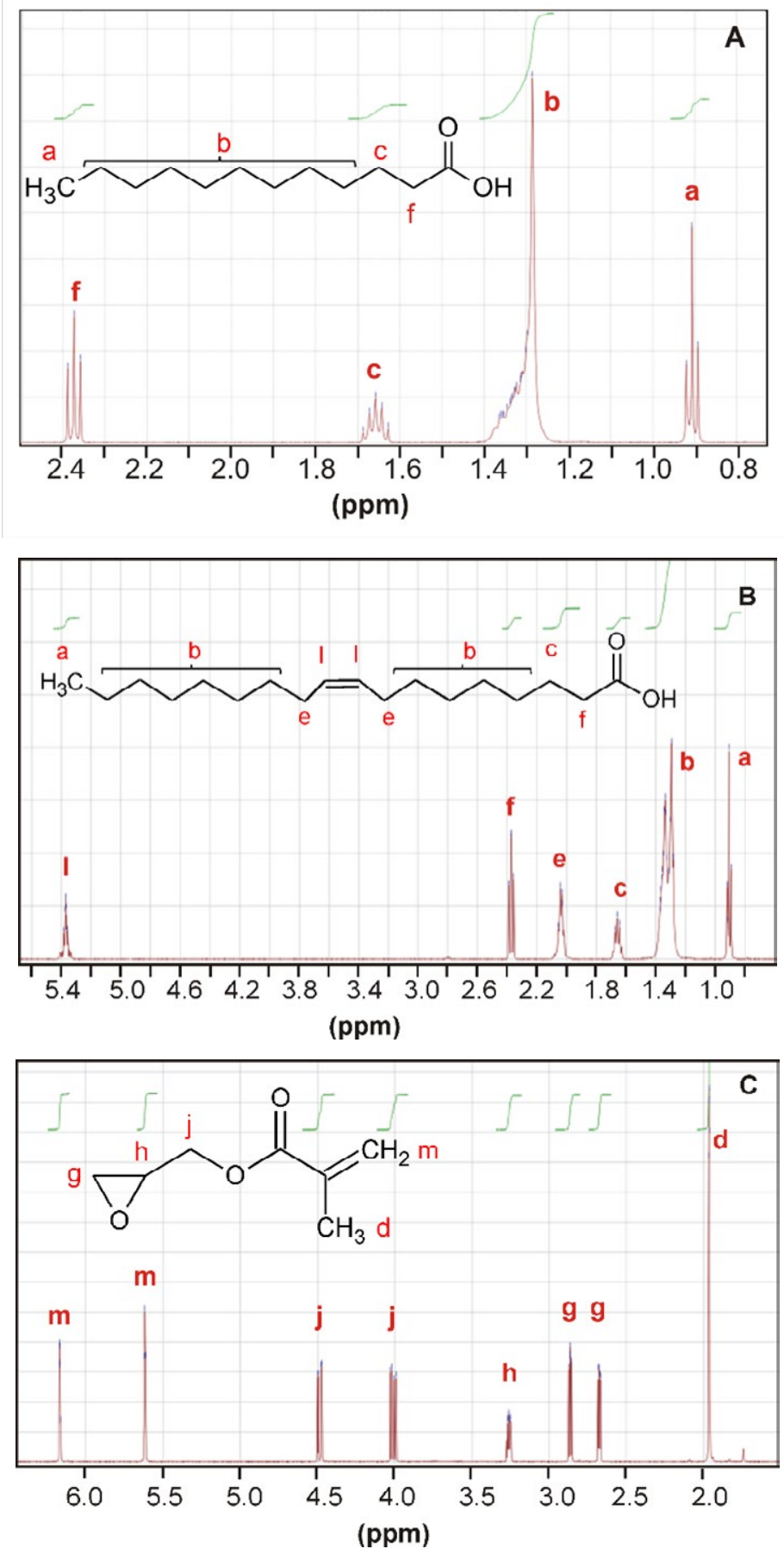

Figure 6. ${ }^{1} \mathrm{H}$ NMR spectra and assignment of peaks: $(\mathrm{A})$ lauric acid, $(\mathrm{B})$ oleic acid and (C) GMA. 
Fig.7(a) and 7(b) present the spectra corresponding to the products of synthesis S5 and S6. It can be seen the presence of a signal at $3.8 \mathrm{ppm}$, which is characteristic of the proton connected to the hydroxyl group generated by the epoxy ring opening ("i"; $\mathrm{CH}-\mathrm{OH})^{32-34}$ and the hydroxyl proton ("k") appears in the region between $3.2-4.6 \mathrm{ppm}^{21,35,36}$. The overlapping and wide range of signals corresponding to protons related with hydroxyl groups that is associated withtheir delocalization due to interactions with other molecules by hydrogen bonding ${ }^{37}$ can produce a decrease in the signals and consequently, the calculation of experimental amounts of protons could be not accurate and thus, do not be comparable with the theoretical ones.Furthermore, the signals associated with ester groups in the region $4-4.5 \mathrm{ppm}$ present higher intensity due to the increase of ester groups as a result of the epoxy-acid addition.On the other hand, the signals corresponding to the epoxy group (2.67-3.25 ppm) decrease almost completely. These results confirm the formation of the methacrylated fatty acid based monomersthrough a chemical route that lead to quite high conversion and relatively pure products.Additionally it should be noticed that both, the unsaturation of oleic acid (proton "I" in Fig. 6) as well as the unsaturation of the acrylate group of GMA (proton "m" in Fig. 6) remained constant after reaction, as can be observed in the ${ }^{1} \mathrm{H}$ NMR spectra; the last result also confirms the absence ofepoxy parallel or side reactions. 


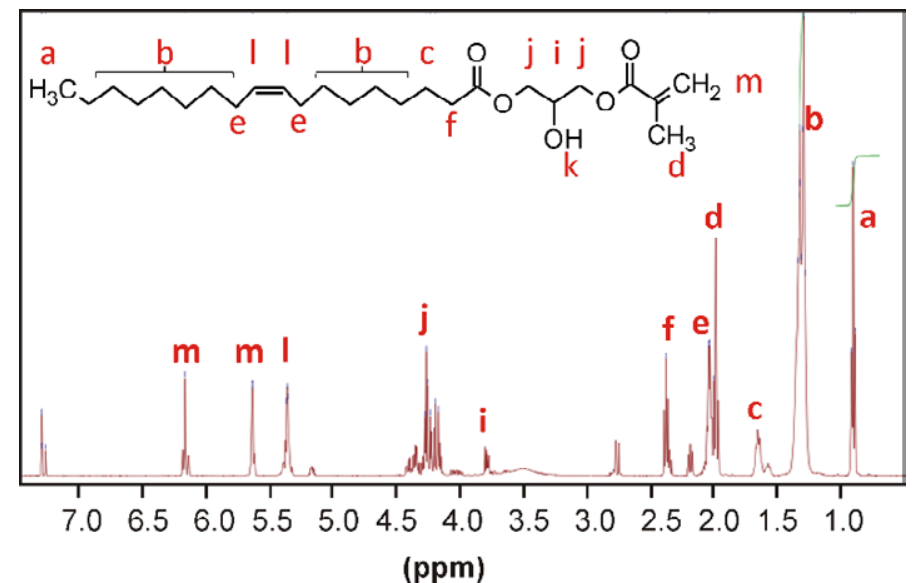

Figure $7(\mathrm{a}) .{ }^{1} \mathrm{H}$ NMR spectra of monomer S5 and assignment of peaks.

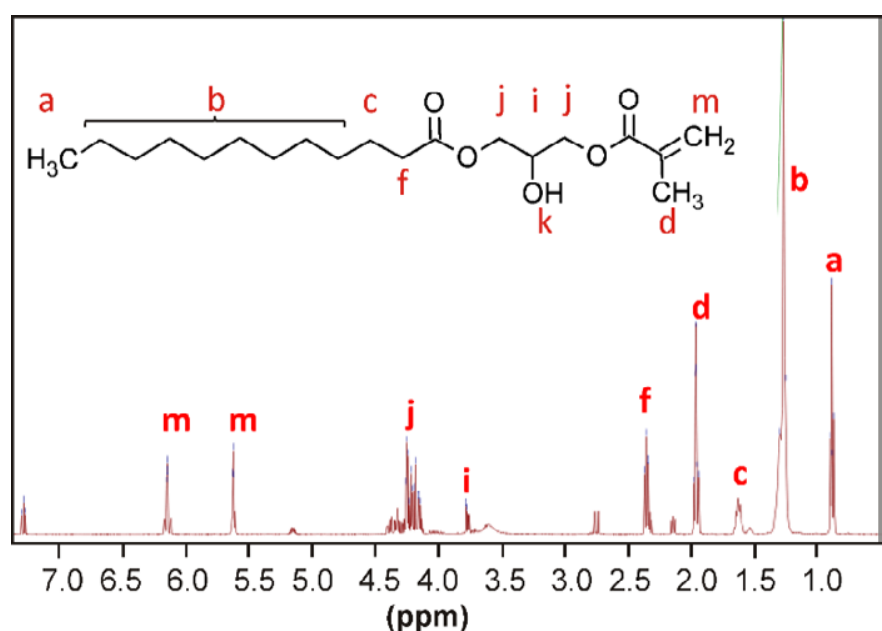

Figure $7(\mathbf{b}) .{ }^{1} \mathrm{H}$ NMR spectra of monomer $\mathrm{S} 6$ and assignment of peaks.

\subsection{Polymerization of fatty acid based monomers and styrene}

The synthesized monomers S5 and S6 were further tested for the obtaining of polymeric materials and thus, reactive mixtures were prepared using $50 \% \mathrm{wt}$. of styrene and two different initiators $\left(\mathrm{BPO}\right.$ and $\left.\mathrm{BF}_{3} . \mathrm{OEt}_{2}\right)$ to allow both free and cationicradical polymerizations, respectively (Table 2).In all cases,homogeneous and mainly transparent materials were successfully obtained, as shown in Fig. 8. 
All polymers present elastomeric (rubbery) characteristics, as can be checked from the dynamic-mechanical response of the samples as a function of the temperature presented in Fig. 9 and 10.From Fig. 9 it is clear that all tan $\delta$ curves present one peak associated to the glass transition temperatures (Tgs) of the obtained polymers. The maximum in the damping factor is observed at higher temperatures when the monomer derived from lauric acid is used, which can be related with the shorter length (i.e. less mobility) of the monomer chain that can form a more compact packing structure in the copolymer. Moreover, both fatty acid based monomers seem to react with styrene in a more extent when the polymerization is conducted through the free radical route, leading to materials with less free volume and higher relaxation temperatures. In addition, from Fig. 10 (shear storage modulus vs. temperature) it can be inferred that the use of the OA or LA based monomersin the free radical polymerization results in materials slightly more rigid at temperatures belowand near $\mathrm{Tg}$ (glassy state) than their counter parts obtained by cationic polymerization, although there are almost no differences between any of the materials in the rubbery zone.

Although radical and ionic (cationic or anionic) initiators are used in chain polymerizations of carbon-carbon unsaturated molecules, they cannot be used indiscriminately, since monomers show varying degrees of selectivity with regard to the type of reactive center involved in their polymerization. Most monomers will undergo polymerization with a radical initiator (vinyl esters, acrylates and methacrylates, among others) although at varying rates. 
However, monomers show high selectivity toward ionic initiators and some of them may not polymerize with cationic initiators. In this way, the terminal carbon-carbon unsaturationsin the synthesized precursors based on oleic and lauric acids is expected to belesser reactive in cationic polymerizations ${ }^{38}$ and therefore MLO-ST-cationic and MLA-ST-cationic resulted in materials with lower Tgs and storage moduli (i.e. lower reticulation degree)than their respective counterparts (MLO-ST-radical and MLA-ST-radical) obtained by free radical polymerization.

Anyhow it is important to remark that neither the cationic nor the free radical polymerization routes were yet optimized regarding catalyst content and curing cycle (time and temperature); the purpose of this section is just to demonstrate that the obtained monomers can be useful in the preparation ofreliable elastomeric materials that combine low cost with environmental advantages (i.e. higher bio-carbon content).

Coming back to the chemical structures of the monomers presented in Fig. 1 and considering also the chemical analysis of the synthesized products, it is clear that difunctional monomers were mainly obtained from the reaction of oleic/lauric acid with GMA. However, if these monomers with just one terminal unsaturation each one were the only species reacting in the copolymerization with the also difunctional styrene, linear copolymers with no rubbery plateau above $\mathrm{Tg}$ would be expected. Thus, the non zero rubbery moduli observed 
above $\mathrm{Tg}$ in Fig. 10 for all the obtained materials is a proof that cross-linked networks are formed during copolymerization.

In the present case, these thermoset polymers only can be formed if the biobased precursors offer to the polymerization functionalities higher than 2 and in this way act as cross-linkers. As was mentioned before, the reaction carboxylic acid-epoxy group can generate several secondary products and some of them with functionalities higher than 2 . Secondary products are hardly observed in GPC chromatographs but can be formed during polymerization reaction where the temperature and time conditions are stronger.In others words, in the further polymerization process these secondary reactions couldbe continued/reactivated, increasing even more the amount of monomers with functionalities higher than 2.
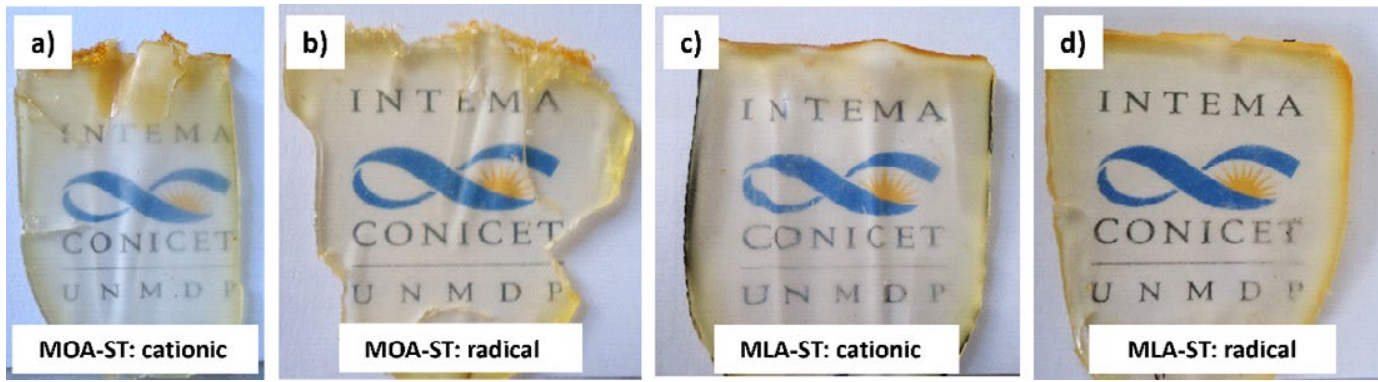

Figure 8. Materials prepared using a) S5 monomer and styrene (50\%) with $1.5 \%$ wt. of BPO. b) S5 monomer and styrene (50\%) with $1.5 \%$ wt. of $\mathrm{BF}_{3} . \mathrm{OEt}_{2}$. c) S6 monomer and styrene (50\%) with $1.5 \%$ wt. of BPO. d) S6 monomer and styrene (50\%) with $1.5 \%$ wt. of $\mathrm{BF}_{3}$. $\mathrm{OEt}_{2}$. 


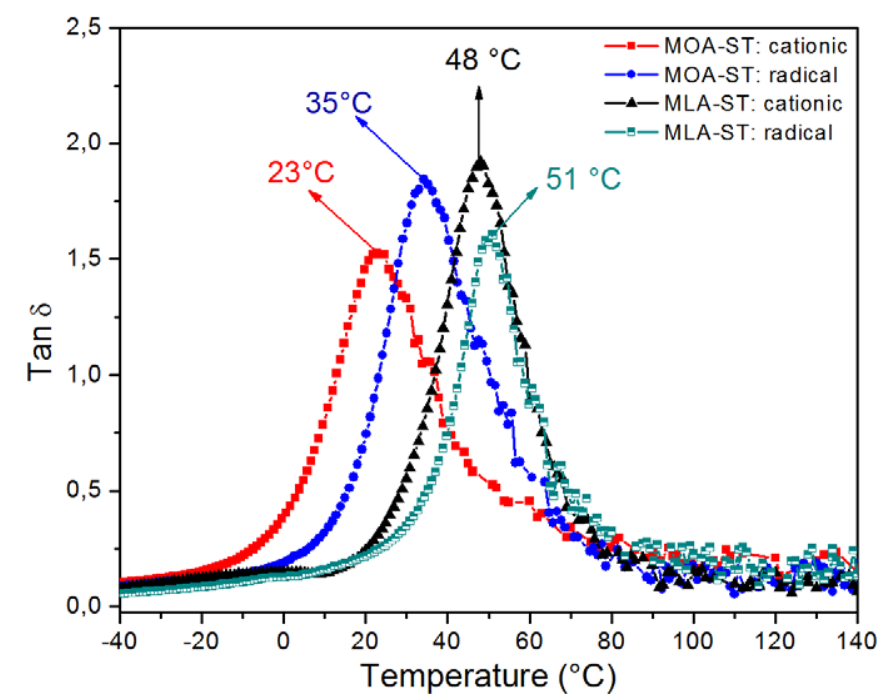

Figure 9. Tan $\delta$ versus temperature curves of the obtained polymers.

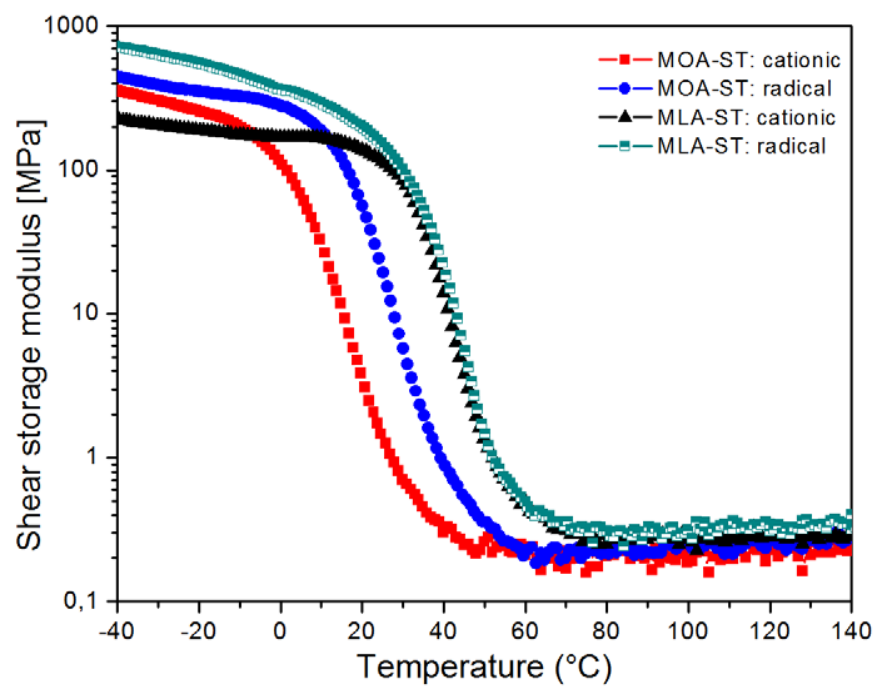

Figure 10. Shear storage modulus versus temperature curves of the obtained polymers.

For a macroscopic demonstration of the shape memory behavior, samples of each material were heated in hot water $\left(60^{\circ} \mathrm{C}\right.$ and $\left.70^{\circ} \mathrm{C}\right)$,formed in " $\mathrm{U}$ " shape and then cooled down to $15^{\circ} \mathrm{C}$ to keep that temporary (fixed) shape. The recovery angles were measured at different times after immersing the samples again in hot water. 
Figure 11 shows, as an example, the sequence of shape recovery forthe sample MLA-ST cured by free radical polymerization at $60^{\circ} \mathrm{C}$. The shape recovery ratios as a function of immersion time were calculated for all the samples and are reported in Table 5. The samples prepared with MLA present the longest times of recovery and thus, lower $\mathrm{Rr}$ at short times and incomplete recovery at $60^{\circ} \mathrm{C}$.Although $60^{\circ} \mathrm{C}$ is a temperature higher than that of the Tgs for all the samples, it seems not to be high enough to allow the complete relaxation of the structure in samples made from MLA. Contrary, at $70^{\circ} \mathrm{C}$ the complete recovery of the original shape (angles of $180^{\circ}$ ) is obtained in very short times (3 and $5 \mathrm{~s})$.

Finally, this preliminary characterization of the copolymers obtained was completed with the evaluation of the water that can be absorbed by the materials at equilibrium. It should be pointed out that water absorption can be a determining effect of the chemo-response of these materials by affecting not only their glass transitions but also their mechanical and shape memory properties ${ }^{39}$.However, after keeping the samples immersed in water at room temperature during 24 hours, we found that the water absorbed was lower than $1.5 \%$ in all cases (being this amount practically the same that the moisture absorbed during storage in room conditions), which makes us expect that their properties will not be much affected even after this long contact with a polar liquid. Nevertheless the complete characterization of the materials obtained as 
well as a more extensive study of their shape memory response is currently in progress and will be will be presented in detail in future works.

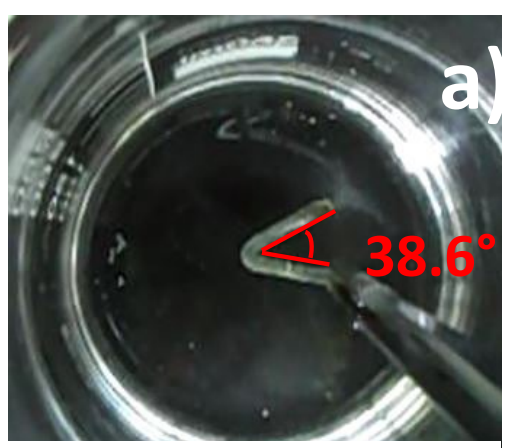

MOA-ST-radical $-60^{\circ} \mathrm{C}$ $-2 \mathrm{~s}$

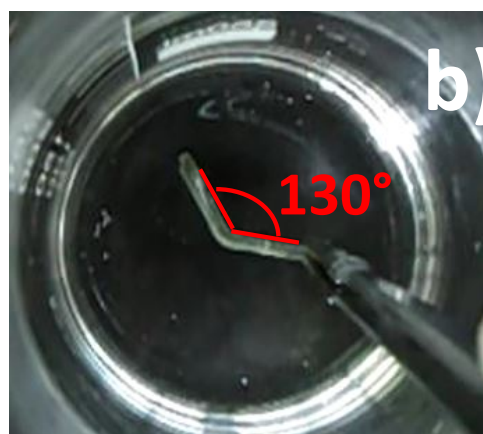

MOA-ST-radical $-60^{\circ} \mathrm{C}$ $-4 \mathrm{~s}$

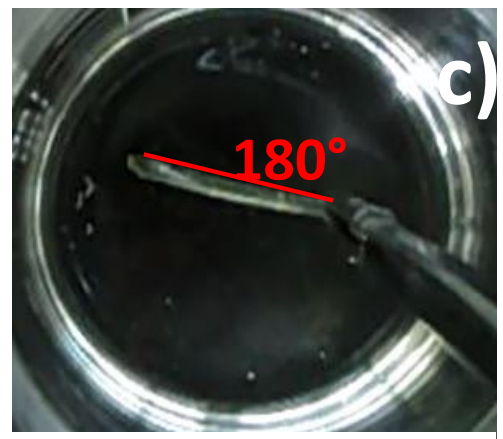

MOA-ST-radical $-60^{\circ} \mathrm{C}$

$-8 \mathrm{~s}$

Figure 11. Sequence of shape recovery of a bar (MLA-ST cured by free radical polymerization) initially deformed at a temperature above $\mathrm{Tg}$ to attain a bent shape.

Time after heating in hot water: a) 2 seconds,b) 4 seconds,c) 8 seconds.

Table 5. Shape recovery ratios as a function of immersion time in hot water.

\begin{tabular}{|c|c|c|c|c|c|c|}
\hline Sample & $\begin{array}{c}\mathrm{Tg} \\
\left({ }^{\circ} \mathrm{C}\right)\end{array}$ & $\begin{array}{c}\text { Water } \\
\text { temperature }\end{array}$ & $\begin{array}{l}\text { Maximum } \\
\text { recuperation }\end{array}$ & \multicolumn{3}{|c|}{$\operatorname{Rr}(\%)$ at different times } \\
\hline $\begin{array}{l}\text { MOA-ST- } \\
\text { cationic }\end{array}$ & 23 & 60 & 4 & $\begin{array}{c}77.8 \\
\text { (at 2 s) }\end{array}$ & $\begin{array}{c}100 \\
\text { (at } 4 \mathrm{~s})\end{array}$ & - \\
\hline $\begin{array}{l}\text { MOA-ST- } \\
\text { radical }\end{array}$ & 35 & 60 & 4 & $\begin{array}{c}76.7 \\
\text { (at } 2 \mathrm{~s} \text { ) }\end{array}$ & $\begin{array}{c}100 \\
\text { (at } 4 \mathrm{~s})\end{array}$ & - \\
\hline $\begin{array}{c}\text { MLA-ST } \\
\text { cationic }\end{array}$ & 48 & 60 & $>12$ & $\begin{array}{c}13.9 \\
\text { (at } 2 \mathrm{~s} \text { ) }\end{array}$ & $\begin{array}{c}33.9 \\
\text { (at } 4 \mathrm{~s})\end{array}$ & $\begin{array}{c}92.8 \\
\text { (at } 12 \mathrm{~s})\end{array}$ \\
\hline $\begin{array}{c}\text { MLA-ST } \\
\text { radical }\end{array}$ & 51 & 60 & $>8$ & $\begin{array}{c}21.4 \\
\text { (at } 2 \mathrm{~s} \text { ) }\end{array}$ & $\begin{array}{c}72.3 \\
\text { (at } 4 \mathrm{~s} \text { ) }\end{array}$ & $\begin{array}{c}86.2 \\
\text { (at } 12 \mathrm{~s})\end{array}$ \\
\hline $\begin{array}{l}\text { MOA-ST- } \\
\text { cationic }\end{array}$ & 23 & 70 & 3 & & $\begin{array}{c}100 \\
\text { (at } 3 \mathrm{~s})\end{array}$ & - \\
\hline $\begin{array}{l}\text { MOA-ST- } \\
\text { radical }\end{array}$ & 35 & 70 & 3 & & $\begin{array}{c}100 \\
\text { (at } 3 \mathrm{~s} \text { ) }\end{array}$ & - \\
\hline $\begin{array}{l}\text { MLA-ST } \\
\text { cationic }\end{array}$ & 48 & 70 & 5 & & $\begin{array}{c}33.0 \\
\text { (at } 3 \mathrm{~s} \text { ) }\end{array}$ & $\begin{array}{c}100 \\
\text { (at } 5 \mathrm{~s} \text { ) }\end{array}$ \\
\hline $\begin{array}{c}\text { MLA-ST } \\
\text { radical }\end{array}$ & 51 & 70 & 5 & & $\begin{array}{c}80.0 \\
\text { (at } 3 \mathrm{~s} \text { ) }\end{array}$ & $\begin{array}{c}100 \\
\text { (at } 5 \mathrm{~s} \text { ) }\end{array}$ \\
\hline
\end{tabular}




\section{Conclusions}

Methacrylated fatty acid monomers have been successfully obtained and exhaustively characterized by different analytical techniques. They were used as polymeric precursors in the reaction with a vinyl monomer as styrene in cationic as well as free radical polymerizations, leading to solid thermoset and highly translucent materials with glass transition temperatures close to room temperature.

The use of lauric acid, the shorter fatty acid, improved the dynamic mechanical properties because the plasticization effect of the free dangling chains in the cured polymer was reduced. Similar effect produced the free radical polymerization that seems to be more effective in the reaction of polymerization, driving to an increase in the glass transition temperature and in the shear storage modulus in the analyzed temperature range. Additionally, shape memory behavior activated by changes in temperature was observed in all the formulations. Even more, variations in the composition of the polymerized materials would tune the Tgs and glass and rubbery moduli, allowing tailoring these shape memory properties for different applications.

These preliminary results ensure that both green monomers can be used to produce functional materials with high bio-carbon contents-

The study and evaluation of more specific properties (mechanical, thermal and optical, among others) that is currently in progress, will allow comparing the 
performance of these greener materials with that of similarsynthetic elastomeric polymers.

\section{Acknowledgments}

Authors acknowledge the financial support provided by the ANPCyT (Grant PICT-2016-2034) and the UNMdP (Project 15/G494/ING500/17).

\section{References}

1. Gandini A. Macromolecules 41: 9491-9504 (2008).

2. Miao S, Wang P, Su Z, Zhang S. ActaBiomater 10: 1692-1704 (2014).

3. Meier MAR, Metzger JO, Schubert US. ChemSoc Rev 36: 1788-1802 (2007).

4. Mosiewicki MA, Aranguren MI. Polymlnt65: 28-38 (2015).

5. Zhang C, Garrison TF, Madbouly SA, Kessler MR.ProgPolymSci71: 91143 (2017).

6. SenihaGüner F, Yağci Y, TuncerErciyes A. ProgPolymSci31: 633-670 (2006).

7. Gunstone FD. Fatty Acid and Lipid Chemistry. Blackie Academic and Professional: New York, (1996).

8. Yadav SK, Schmalbach KM, Kinaci E, Stanzione JF, Palmese GR.EurPolym J 98: 199-215(2018).

9. LI F, Larock RC. Biopolymers from Soybean and Other Natural Oils. In: Mohanty A, Misra M, Drzal L (eds) Natural fibers, biopolymers, and biocomposites. Boca Ratón: CRC Press-Taylor \& Francis Group, (2005).

10. Lu Y, Larock RC. ChemSusChem2: 136-147 (2009).

11. Xia Y, Quirino RL, Larock RC. J Renew Mater1: 3-27 (2013). 
12. Montero De Espinosa L, Meier MAR. EurPolymJ47: 837-852 (2011).

13. Vilela C, Rua R, Silvestre AJD, Gandini A.Ind Crops Prod32: 97-104 (2010).

14. Bunker SP, Wool RP. J PolymSci Part A PolymChem40: 451-458 (2002).

15. Moreno M, Goikoetxea M, Barandiaran MJ. J PolymSci Part A PolymChem50: 4628-4637 (2012).

16. Lee W. J ApplPolymSci47: 61-71 (1993).

17. La Scala JJ, Sands JM, Orlicki JA, Robinette EJ, Palmese GR.Polymer45: 7729-7737 (2004).

18. Kiatsimkul P pahn, Suppes GJ, Hsieh F hung, Lozada Z, Tu YC.Ind Crops Prod27: 257-264 (2008).

19. Can E, La Scala JJ, Sands JM, Palmese, G R. J ApplPolymSci106: 3833-3842 (2007).

20. Dey T. PolymInt56: 853-859 (2007).

21. Campanella A, La Scala JJ, Wool RP. J AppIPolymSci119: 1000-1010 (2011).

22. Liu C, Qin H, Mather PT. J Mater Chem17: 1543-1558 (2007).

23. Huang WM, Zhao Y, Wang CC, Ding Z, Purnawali H, Tang C, Zhang JL. J Polym Res19: 9952 (2012).

24. Meiorin C, Aranguren MI, Mosiewicki MA. Polymint61:735-742 (2012).

25. Meiorin C, Aranguren MI, Mosiewicki MA. J ApplPolymSci124: 50715078 (2012).

26. Urbanski J. Handbook of Analysis of Synthetic Polymers and Plastics.John Wiley \& Sons, (1977).

27. Stitt BRM. Automated determination of the hydroxyl number (HN) according to ASTM E 1899-08 and DIN 53240-2 (1990).

28. Zheng X, Zhou S, Li X, Weng J. Biomaterials27: 4288-4295 (2006).

29. Bellamy LJ. The Infra-red Spectra of Complex Molecules.Third edit. London: Chapman and Hall Ltd., (1975). 
30. Socrates G. Infrared and Raman Characteristic Group Frequencies Contents,(2004).

31. Shechter L, Wynstra J. IndEngChem48: 86-93 (1956).

32. Meiorin C, Aranguren M, Mosiewicki M. EurPolym J67: 551-560 (2015).

33. Campanella A, La Scala JJ, Wool RP. PolymEng49: 2384-2392 (2009).

34. Singh RP, Khait M, Zunjarrao SC, Korach CS, Pandey, G. J Nanomater2010:1-13 (2010).

35. Caillol S, Desroches M, Boutevin G, Loubat C, Auvergne R, Boutevin B. Eur J Lipid SciTechno/114: 1447-1459 (2012).

36. Zhang Y, Li H, Dong J-Y, Hu, Y. PolymChem5: 105-115 (2014).

37. Agarwal V, Unser R, Fink U, Faelber K, Reif B. J Am ChemSoc132: 3187-3195 (2010).

38. Su W-F. Principles of Polymer Design and Synthesis.Lecture Notes in Chemistry Vol. 82. Springer, Berlin, Heidelberg(2013).

39. Huang WM, Yang B, An L, Li C, Chan YS. ApplPhysLett86:1-3 (2005). 